\title{
Attempt towards a novel classification of triple-negative breast cancer using immunohistochemical markers
}

\author{
YAN-XI LIU ${ }^{1}$, KE-REN WANG ${ }^{1}$, HUA XING $^{1}$, XU-JIE ZHAI ${ }^{1}$, LI-PING WANG ${ }^{2}$ and WAN WANG ${ }^{1}$ \\ Departments of ${ }^{1}$ Breast Surgery and ${ }^{2}$ Pathology, China-Japan Union Hospital of Jilin University, \\ Changchun, Jilin 130033, P.R. China
}

Received April 5, 2015; Accepted May 24, 2016

DOI: $10.3892 / \mathrm{ol} .2016 .4778$

\begin{abstract}
Significant efforts have been made to gain a better understanding of the heterogeneity of triple-negative breast cancers from the histological to the molecular and genomic levels. In this study, we attempted to bring forward gene expression subtypes of triple-negative breast cancer (TBNC) to the clinic, by translating gene stratification to clinically accessible immunohistochemical (IHC) classification. Using IHC analysis, we categorized 154 TBNC cases into three main subclasses. Differences in the frequencies of basic characteristics and clinicopathological parameters between the subtypes were examined using Chi-square tests. We defined three main groups among the 154 triple-negative cases. The basal-like (BL) group expressed cytokeratin (CK) 5/6 and/or CK14 (83 cases), the $\mathrm{AR}^{+}$group demonstrated positivity for androgen receptor (18 cases), and the final group exhibited a $\mathrm{CD} 44^{+} \mathrm{CD} 24^{-/ \text {low }}$ phenotype (39 cases). There were three overlapping cases between the BL subgroup and the $\mathrm{CD} 44^{+} \mathrm{CD} 24^{-/ \text {low }}$ phenotype subgroup, and 11 unclassified cases. In this new IHC classification, three subcategories exhibited a statistical difference with regard to age, tumor size, histological grade, tumor necrosis, Ki67 labeling index, relapse-free survival, breast cancer-specific survival and response to chemotherapy. According to our definition, the BL group and CD $44^{+} \mathrm{CD} 24^{-/ \text {low }}$ phenotype could be observed in tumors that were not triple-negative, and BL tumors that were triple-negative demonstrated almost undistinguishable clinicopathological characteristics compared with BL tumors that were not triple-negative. The same observation was made with $\mathrm{CD} 44^{+} \mathrm{CD} 24^{-/ \text {low }}$ tumors that were triple-negative vs. $\mathrm{CD} 44^{+} \mathrm{CD} 24^{-/ \text {low }}$ tumors that were not. The $\mathrm{AR}^{+}$group demonstrated undistinguishable clinicopathological characteristics compared with the luminal subtype. We successfully
\end{abstract}

Correspondence to: Dr Wan Wang, Department of Breast Surgery, China-Japan Union Hospital of Jilin University, 126 Xiantai Blvd, Changchun, Jilin 130033, P.R. China

E-mail:wangwan0106@yahoo.com

Key words: triple-negative breast cancer, classification, clinicopathological characteristics, prognosis distinguished three subtypes exhibiting diverse clinicopathological and prognostic characteristics with the minimum use of IHC markers.

\section{Introduction}

Triple-negative breast cancer (TNBC), an aggressive type of breast cancer, lacks effective targeted therapy due to the absence of hormone receptors and human epidermal growth factor-2 (HER2). Therefore, considerable effort has been made to identify subclasses of TNBC with distinct characteristics that may potentially be targeted in the clinic.

In 2008, Cheang et al (1) revealed that TNBC cases that positively expressed epidermal growth factor receptor (EGFR) or cytokeratin (CK) 5/6 demonstrated a shorter survival time and poorer response to chemotherapy, but might benefit from EGFR-targeted therapy (2-7). Another marker in TNBC with potential prognostic and therapeutic value, androgen receptor (AR), has drawn particular attention since 2010 (8). In recent years, studies have progressed to the molecular level. Prat et al (9) investigated the correlation between TNBC molecular subtypes and the PAM50 intrinsic subtypes as well as the claudin-low subtype. These authors observed that the majority of TNBCs were either basal-like (39 to 54\%) or claudin-low ( $25 \%$ to $39 \%$ ), followed by HER2-enriched and luminal. However, Lehmann et al (10) reported another classification based on gene expression profiles of 587 TNBCs: basal-like 1 (BL1), basal-like 2 (BL2), immunomodulatory (IM), mesenchymal (M), mesenchymal stem-like (MSL), and luminal androgen receptor (LAR). Further analysis narrowed these down to three main groups (BL, mesenchymal-like and LAR), which demonstrated different responses to cytotoxic and targeted therapies.

These apparently different classifications may be related (11). Basal-like in the PAM50 assay encompassed the TNBC BL subtypes defined by Lehmann as well as certain tumors classified as IM and $\mathrm{M}(10,12)$. In addition, MSL describes a similar group of claudin-low cancers while LAR shares a number of gene expression features of estrogen receptor (ER)-positive and HER2-enriched cancers $(10,12)$. Thus, despite the lack of consensus, it appears reasonable to predict that there are three basic subtypes within TNBC (11,13-15).

Gene expression-based classification significantly changes our understanding of the heterogeneity of TNBC. However, 
it raises the question of how this sophisticated approach can be translated into a practical and clinically accessible diagnostic test, given that gene identification is currently not feasible for large-scale application on routine formalin-fixed paraffin-embedded clinical samples (16). In this study, we adopt the immunohistochemistry (IHC) methodology. We examined the IHC profile of 154 TNBC cases and identified three subtypes exhibiting diverse clinicopathological and prognostic characteristics with the minimum use of biomarkers.

\section{Patients and methods}

Patient selection. We collected breast cancer cases with sufficient medical records from the Department of Breast Surgery, China-Japan Union Hospital of Jilin University, China, between January 2006 and November 2014. Inclusion criteria for this study were: i) female; ii) primary stage I-III invasive breast cancer; iii) no neoadjuvant chemotherapy or radiotherapy prior to surgery; iv) breast tissue samples available for study. All of the subjects underwent surgical treatment according to standard treatment protocols. Clinicopathological parameters including age, histological subtype, tumor size, histological grade, nodal status, and presence of lymphovascular invasion and tumor necrosis were noted. The histological subtype and histological grade were assessed in accordance with standard guidelines and confirmed independently by two pathologists from the Department of Pathology at the China-Japan Union Hospital of Jilin University. The median follow-up time was 68 months (range, 2 to 108 months). The study was approved by the ethics committee of Jilin University.

Immunohistochemistry and scoring. Immunohistochemical staining was performed according to the following protocol. Sections from paraffin-embedded tissue microarrays were cut to $4 \mu \mathrm{m}$, deparaffinized in xylene and rehydrated through graded alcohols. Microwave epitope retrieval was performed in target retrieval pH 6.0 (Dako, Carpinteria, CA, USA) for ER and HER2, high pH target retrieval for CK5/6 (Dako), or $10 \mathrm{mM}$ citrate buffer ( $\mathrm{pH}$ 6.0) for $10 \mathrm{~min}$ followed by cooling for $15 \mathrm{~min}$ at room temperature for claudins.

The following antibodies were used: clone SP1 against ER (1:300 dilution; Dako), clone SP2 against progesterone receptor (PR; 1:250 dilution; Neomarkers, Fremont, CA, USA), clone SP3 against HER2 (1:200 dilution; Neomarkers), clone SP6 against Ki67 (1:200 dilution; Neomarkers), clone D5/16B4 against CK5/6 (1:100 dilution; M7237; Dako), clone LL002 against CK14 (1:20; NCL-LL002; Novocastra, Newcastle upon Tyne, UK), clone E30 against EGFR (1:50; M7239; Dako), clone NCH-38 against E-cadherin (1:50, Dako), clone V9 against vimentin (1:150, Dako), clone Z23.JM against claudin 3 (1:300; Invitrogen Life Technologies, Carlsbad, CA, USA), clone Ab15104 against claudin 4 (1:300, Abcam), clone Ab27287 against claudin 7 (1:400; Abcam, Cambridge, MA), clone AR27 against AR (1:100, NCL-AR-318), clone 156-3C11 against CD44 (1:100, Cell Signaling Technology, Inc., Danvers, MA, USA), and clone Ab2-SN3b against CD24 (1:100 Neomarkers).

Staining results were assessed by two pathologists in a blinded fashion. For ER, PR and AR status, stains were considered positive if at least $1 \%$ of tumor nuclei demonstrated positivity, regardless of the intensity (1 to $3+$ ). For HER2 status, stains were considered positive if at least $30 \%$ of tumor cells exhibited a cell membrane staining score of $3+$. There are no commonly accepted cut-off points reported for EGFR. Membranous EGFR staining in $>1 \%$ of tumor cells was used as the definition of protein positivity according to the Dako criteria provided in the pharmDx kit instructions. For Ki67, the mean percentage of nuclear positivity was evaluated in a stepwise manner; i.e. 1, 2, 3, 5, 10, 15, 20, 25, 30, 35, 40, 50, $60,70,80$ and $90 \%$. For CK5/6 and CK14, staining was scored as positive when more than $10 \%$ of the tumor cells demonstrated cytoplasmic and/or membranous staining. E-cadherin expression was analyzed semi-quantitatively according to the percentage of cells demonstrating membrane positivity: $0,0-10 \% ; 1+, 10-30 \% ; 2+, 30-70 \% ; 3+,>70 \%$. E-cadherin expression was considered positive when scores were $\geq 2$ and negative when scores were $\leq 1$. Any distinct positive staining of the tumor cytoplasm in cancer cells with the vimentin antibody was regarded as positive vimentin expression. Claudin immunoreactivity was assessed based on a combined score of the extension and intensity of membrane expression. The extension was registered as the percentage of positive cells for claudins: $0,0 \% ; 1+,<25 \% ; 2+, 25-50 \% ; 3+,>50 \%$. The intensity of membrane immunostaining was graded as: 0 (negative); 1 (weak); 2 (moderate); 3 (strong). The two scores were multiplied to give an overall score of $0-9$, of which 0 was considered negative, 1-2 was considered weak, 3-6 moderate, and 9 strong staining. Negative and weak expression was considered as low, while moderate and strong were considered high. Tumors with low expression of all three claudins were defined as claudin-low. For CD44 and CD24, stains were scored positive when more than $10 \%$ of the tumor cells exhibited membranous staining. We considered a tumor to have a cancer stem cell (CSC) phenotype when the frequency of $\mathrm{CD} 44^{+} \mathrm{CD} 24^{-/ \text {low }}$ cells was more than $10 \%$, as previously described in other studies $(17,18)$. Any discordant scores were reviewed together by the two scorers to obtain a consensus.

Definition of breast cancer subtypes by IHC. Identifying subgroups of TNBC is of significance for a better understanding of this complex disease. By drawing on the work of Prat et al $(9,13)$ and Lehmann et al $(10,12)$ on gene expression subtypes, we attempted for the first time to classify TNBC into three subsets using IHC markers. Our main aim was to seek IHC surrogates that potentially identify the main three gene expression subtypes. Here are certain noteworthy points from the studies of Prat et al and Lehmann et al: i) TNBC subtypes defined by Lehmann differentially correlate with the PAM50 intrinsic subtypes $(12,13)$. BL1, BL2, IM and $\mathrm{M}$ cases are primarily composed of the BL intrinsic subtype $(99 \%, 95 \%$, $84 \%$ and $97 \%$, respectively), while $~ 50 \%$ of MSL cases and none of LAR cases have the BL intrinsic subtype (12). Therefore, the vast majority of non-basal TNBCs are MSL and LAR tumors. In addition, BL1, BL2, IM and M subtypes express higher levels of basal cytokeratin expression (i.e., CK5/6 and CK14), while tumors in the MSL category exhibit significantly lower basal cytokeratin expression and LAR tumors lack basal cytokeratin expression $(10,12)$. ii) LAR shares a number of gene expression features of $\mathrm{ER}^{+}$and HER2-enriched cancers (10). AR protein is highly expressed within the LAR subgroup, 
on average $>10$-fold higher than all other subtypes (10). iii) MSL is characterized by enrichment for gene expression patterns associated with epithelial-to-mesenchymal (ETM) transition $(10,12,19)$. A portion of the MSL subtypes also are enriched for the CSC-like phenotype $(10,12,19)$, and exhibit low expression of tight junction proteins including claudin 3,4 and $7(10,12,19)$, consistent with a group of cancers previously described as claudin-low (9). iv) The three main subtypes (BL, mesenchymal-like and LAR) defined by Lehmann et al (10) are concordant with the three main groups previously identified by Prat et al (BL, claudin-low and luminal/HER2-enriched) (13) and by Neve et al (20) and Kao et al (21), based upon cell lines alone (basal A, associated with the ETS pathway and BRCA1 signatures and resembling BL tumors; basal B, exhibiting mesenchymal and stem/progenitor cell characteristics; and luminal, exhibiting an ER signature and resembling luminal $\mathrm{A} / \mathrm{B}$ tumors).

Together, it appears feasible to translate the gene expression subtypes into three IHC subtypes. Based on the first point above, triple-negative cases which also positively express either $\mathrm{CK} 5 / 6$ or CK14 are referred to as the 'BL' group in this article. Therefore, the BL subgroup in this article likely encompasses the BL1, BL2, IM and M subtypes and a small proportion of the MSL tumors that express basal cytokeratin. Based on the second point, triple-negative cases which also positively express $\mathrm{AR}$ are referred to as the $\mathrm{AR}^{+}$group. However, selecting IHC marker panels to define the third group is relatively challenging. According to the classification defined by Lehmann et al, the majority of the third group consists of MSL tumors that lack basal cytokeratin expression (12), whereas according to Prat et al (13), the third group should be claudin-low. Although MSL and claudin-low share certain similar features, they are not synonymous. All MSL tumors are associated with EMT transition $(10,11)$, which is characterized by downregulation of E-cadherin and occludin and induction of mesenchymal marker proteins including vimentin and fibronectin (22-25), while only a portion of MSL cases are claudin-low, enriched in CSC-like features with an absence of claudin proteins. Therefore, in order to distinguish the most appropriate IHC surrogates for the third group, we explored the ETM phenotype (evaluating vimentin and E-cadherin expression), CSC-like phenotype (analyzing CD44 and CD24 expression), and claudin 3, 4 and 7 expression in all triple-negative cases, and then defined the third group as vimentin ${ }^{+}$and $\mathrm{E}$-cadherin-; $\mathrm{CD} 44^{+} \mathrm{CD} 24^{- \text {-low }}$ phenotype; low expression of all three claudins, respectively. Vimentin and E-cadherin are well-established and widely accepted as markers for EMT (20-23), while $\mathrm{CD} 44^{+} \mathrm{CD} 24^{- \text {llow }}$ is a known marker for the CSC-like phenotype $(9,21,26,27)$.

Statistical analysis. Differences in the frequencies of basic characteristics and clinicopathological parameters among breast cancer subtypes were examined using Chi-square tests, or Fisher's exact test in the case of less than five expected cases. Relapse-free survival (RFS) was defined as the time from the date of diagnosis to the date of relapse of breast cancer, including locoregional recurrence and/or distant metastasis. Breast cancer-specific survival (BCSS) was defined as the date of a patient's diagnosis of breast cancer until mortality. Survival times were censored if the primary or underlying cause of mortality was not breast cancer, or if the patient was still alive on December 30, 2014 (the date when the outcome data were collected). Survival curves were obtained using the Kaplan-Meier method and differences in survival among the breast cancer subtypes were assessed by the log-rank test. Prognostic analyses used the Cox regression method. Univariate analyses tested classical clinicopathological features: age ( $>50$ vs. $\leq 50$ ), pathological tumor size (pT2-3 vs. pT1), lymph node status (positive vs. negative), histological grade (2 or 3 vs. 1), necrosis (marked vs. minimal or absent), Ki67 (>30\% vs. $\leq 30 \%$ ), adjuvant chemotherapy (performed vs. not performed). The findings were analyzed using SPSS statistical software for Windows, version 18 (SPSS, Inc., Chicago, IL, USA. All statistical tests were two-sided, and $\mathrm{P}<0.05$ was considered to indicate a statistically significant difference.

\section{Results}

Patient characteristics. There were a total of 2407 breast cancer patients receiving surgery at the China-Japan Union Hospital of Jilin University between January 2006 and November 2014. Among these, 1646 cases that had informative IHC results were included in the study. The median age at diagnosis in the study population was 54 years (range, 23-87 years). Mastectomy was performed in $78.3 \%$ of cases (1289/1646), and 21.7\% (357/1646) underwent breast conserving surgery. Following surgery, $82.6 \%(1360 / 1646)$ received adjuvant chemotherapy. The remaining 286 (17.4\%) patients did not receive any adjuvant systemic chemotherapy. The median follow-up time was 68 months (range, 2 to 108 months). Of the 1646 patients, 154 had triple-negative breast cancer (TNBC). The clinicopathological characteristics and IHC profiles of the TNBC cases and other types of breast cancer (non-TNBC) are presented in Table I. The Chi-square test revealed a statistically significant difference in tumor size, histological grade, tumor necrosis and Ki67 labeling index between TNBC and non-TNBC patients. The two groups also differed in the levels of AR, CK5/6, CK14, EGFR, E-cadherin, vimentin, claudin 3, 4 and 7 expression and $\mathrm{CD} 44^{+} \mathrm{CD} 24^{- \text {-low }}$ phenotype (Fig. 1). TNBCs had a statistically larger percentage of tumors that were positive for CK5/6 (57.8\%), CK14 (39.6\%), EGFR (59.0\%), vimentin (44.2\%) and CD44 ${ }^{+} \mathrm{CD} 24^{-/ \text {low }}$ phenotype $(27.3 \%)$ compared with non-TNBCs $(2.2 \%, 2.1 \%, 6.8 \%$, $7.2 \%$ and $2.4 \%$, respectively). AR, E-cadherin, and claudins 3,4 and 7 staining was greater in non-TNBCs $(83.2 \%, 71.7 \%$, $97.6 \%, 97.2 \%$ and $97.4 \%$, respectively), whereas the positivity for these five markers in TNBCs was $11.7 \%, 43.5 \%, 68.2 \%$, $74.0 \%$ and $72.7 \%(\mathrm{P}=0.000)$.

New IHC classification of TNBC. As described in the Patients and methods section, we defined triple-negative cases which also positively expressed either CK5/6 or CK14 as the BL group, triple-negative cases which also positively expressed $\mathrm{AR}$ as the $\mathrm{AR}^{+}$group, and respectively defined the third group as vimentin ${ }^{+}$and $\mathrm{E}$-cadherin-; $\mathrm{CD}_{4} 4^{+} \mathrm{CD} 24^{- \text {/low }}$ phenotype; low expression of claudins 3,4 and 7. A comparison of these three different classifications is shown in Fig. 2. A lower level of overlap was observed between the BL group and the third group when the third group was defined as $\mathrm{CD} 44^{+} \mathrm{CD} 24^{-/ \mathrm{low}}$ phenotype, and the proportion of unclassified 
Table I. Clinicopathological characteristics of TNBC and non-TNBC patients.

\begin{tabular}{|c|c|c|c|c|c|c|c|}
\hline & \multirow{3}{*}{ Characteristics } & \multirow{3}{*}{$\begin{array}{c}\text { TNBC } \\
154\end{array}$} & \multirow{3}{*}{$\begin{array}{c}\text { Non-TNBC } \\
1492\end{array}$} & \\
\hline & & & & & & & \multirow{2}{*}{ P-value } \\
\hline \multirow{2}{*}{ Characteristics } & \multirow{2}{*}{$\begin{array}{l}\text { TNBC } \\
\mathrm{n}=154\end{array}$} & \multirow{2}{*}{\multicolumn{2}{|c|}{$\begin{array}{l}\text { Non-TNBC P-value } \\
\quad n=1492\end{array}$}} & & & & \\
\hline & & & & Vimentin & & & $<0.001$ \\
\hline Age & & & 0.649 & Negative & 86 & 1385 & \\
\hline$\leq 50$ & 85 & 852 & & Positive & 68 & 107 & \\
\hline$>50$ & 69 & 640 & & Claudin 3 & & & $<0.001$ \\
\hline Family history of breast cancer & & & 0.131 & Negative & 49 & 36 & \\
\hline No & 141 & 1411 & & Positive & 105 & 1456 & \\
\hline Yes & 13 & 81 & & Claudin 4 & & & $<0.001$ \\
\hline Histological type & & & & Negative & 40 & 42 & \\
\hline Invasive ductal carcinoma & 93 & 1082 & & Positive & 114 & 1450 & \\
\hline Invasive lobular carcinoma & 5 & 143 & & Claudin 7 & & & $<0.001$ \\
\hline Medullary carcinoma & 13 & 82 & & Negative & 42 & 39 & \\
\hline Metaplastic carcinoma & 12 & 78 & & Positive & 112 & 1453 & \\
\hline Apocrine carcinoma & 13 & 78 & & $\mathrm{CD} 44^{+} \mathrm{CD} 24^{-/ \mathrm{low}}$ & & & $<0.001$ \\
\hline Others & 6 & 29 & & No & 112 & 1456 & \\
\hline Pathological tumor size & & & 0.002 & Yes & 42 & 36 & \\
\hline pT1 & 58 & 792 & & RFS event & & & \\
\hline pT2-3 & 96 & 700 & & No & 104 & 1208 & \\
\hline Histological grade & & & $<0.001$ & Yes & 50 & 284 & \\
\hline 1 & 23 & 228 & & Chemotherapy & & & \\
\hline 2 & 34 & 943 & & No & 31 & 255 & \\
\hline 3 & 97 & 321 & & Yes & 123 & 1237 & \\
\hline $\begin{array}{l}\text { Pathological axillary lymph } \\
\text { node status } \\
\text { Negative }\end{array}$ & 91 & 820 & 0.326 & $\begin{array}{l}\text { Mean survival time } \\
(95 \% \mathrm{CI})\end{array}$ & $\begin{array}{c}86.3 \\
(79.7-93.1)\end{array}$ & $\begin{array}{c}98.7 \\
(81.2-114.5)\end{array}$ & \\
\hline
\end{tabular}

$63 \quad 672$

Lymphovascular invasion

Absent

0.707

Present

Necrosis

Minimal or absent

Marked

Ki67

$\leq 30 \%$

$>30 \%$

AR

Negative

Positive

CK5/6

Negative

Positive

CK14

Negative

Positive

EGFR

Negative

Positive

E-cadherin

Negative

Positive

Table I. Continued.

TNBC, triple-negative breast cancer; AR, androgen receptor; CK, cytokeratin; EGFR, epidermal growth factor receptor; RFS, relapse free survival; CI, confidence interval.

$<0.001$

$89 \quad 1368$

$65 \quad 124$

$72 \quad 1125$

$82 \quad 367$

$136 \quad 251$

$18 \quad 1241$

$65 \quad 1459$

$89 \quad 33$

$93 \quad 1461$

$61 \quad 31$

$94 \quad 1390$

$60 \quad 102$

$87 \quad 422$

$67 \quad 1070$ cases was also relatively smaller in this classification model. Therefore, the three subtypes of TNBC designated in this study are the BL group (83 cases), $\mathrm{AR}^{+}$group (18 cases), and $\mathrm{CD} 44^{+} \mathrm{CD} 24^{-/ \text {low }}$ phenotype (39 cases). Eleven cases that were unclassified and three cases that overlapped between the BL $<0.001$ group and $\mathrm{CD} 44^{+} \mathrm{CD} 24^{- \text {llow }}$ phenotype were excluded in the following study.

The clinicopathological characteristics of each TNBC $<0.001$ subtype are shown in Table II. When a difference among the three groups was detected, multiple comparison was carried out to assess where the difference lies. The Chi-square test revealed that the three subcategories exhibited significantly different characteristics in terms of age, tumor size, histological grade, presence/absence of tumor necrosis and Ki67 labeling index. Multiple comparison further demonstrated that the three subtypes differed significantly from each other in histological grade and tumor necrosis, but not in age, tumor size or Ki67 labeling index. The histological grade of the $\mathrm{CD} 44^{+} \mathrm{CD} 24^{-/ \text {low }}$ subtype was often grade $3(53.8 \%)$ or grade $2(28.2 \%)$, which was lower than tumors in the BL group (grade 3,81.9\%; grade 2,14.4\%), and higher than those in the $\mathrm{AR}^{+}$group (grade 3, 16.7\%; grade 2, 33.3\%). A total of $38.5 \%$ 


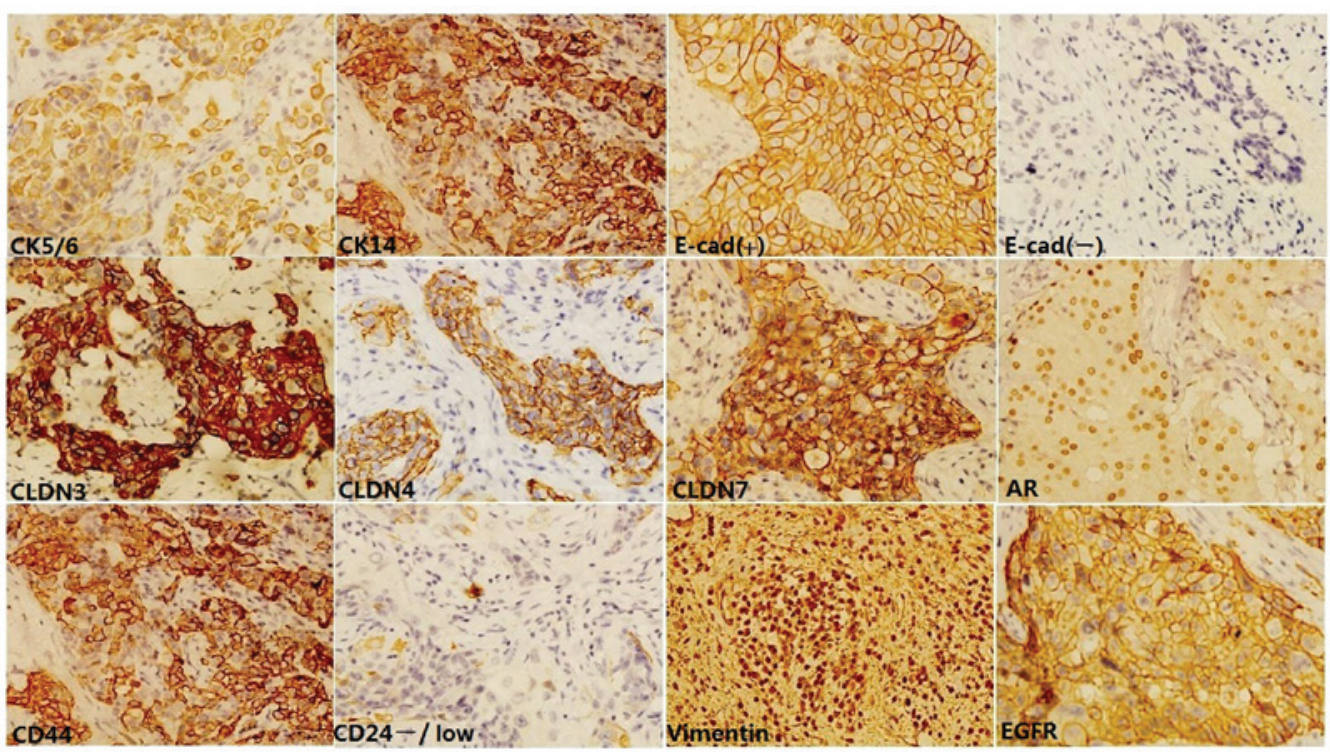

Figure 1. Representative hematoxylin and eosin staining of immunohistochemical biomarkers. Magnification, x200. CK, cytokeratin; E-cad, E-cadherin; CLDN, claudin; AR, androgen receptor; EGFR, epidermal growth factor receptor.
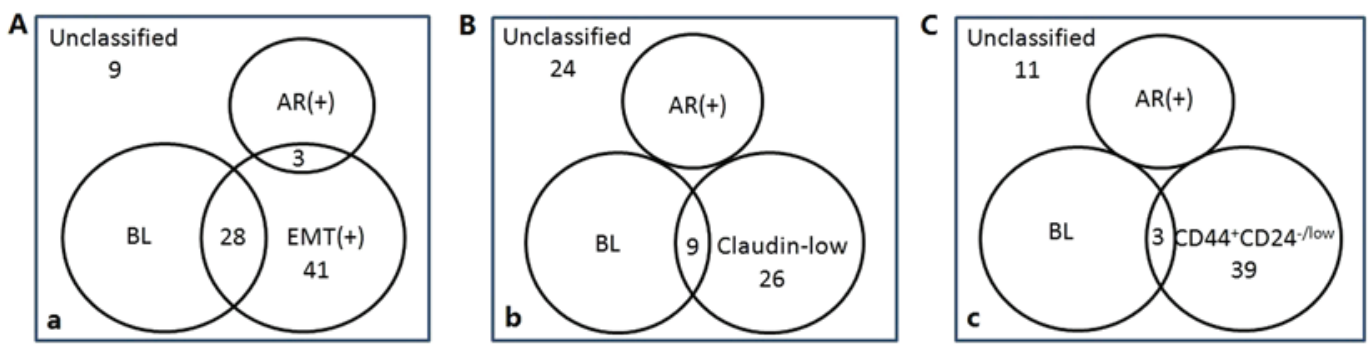

Figure 2. Comparison of three different classifications. (A) The third group is defined as positive for epithelial-to-mesenchymal transition markers vimentin ${ }^{+}$ and E-cadherin. (B) The third group is defined as claudin-low: low expression of claudin 3, 4 and 7 (C). The third group is defined as $\mathrm{CD} 44^{+} \mathrm{CD} 24^{-} /$low phenotype. AR, androgen receptor; BL, basal-like; EMT, epithelial-to-mesenchymal transition.

of $\mathrm{CD} 44^{+} \mathrm{CD} 24^{-/ \text {low }}$ subtype cases demonstrated marked tumor necrosis, a percentage intermediate between that of the BL group (57.8\%) and the $\mathrm{AR}^{+}$group (11.1\%).

As for age and tumor size, although the Chi-square test revealed a statistically significant difference among the three subcategories, multiple comparison revealed that only the difference between the $\mathrm{BL}$ group and $\mathrm{AR}^{+}$group was significant. Patients with $\mathrm{AR}^{+}$tumors were older than patients with BL tumors ( $>50$ years, $66.7 \%$ vs. $37.3 \%$; multiple comparison test, $\mathrm{P}=0.0226)$. A total of $55.5 \%$ of $\mathrm{AR}^{+}$tumors measured $\leq 2 \mathrm{~cm}$ (pT1) while $28.9 \%$ of BL tumors were pT1 (multiple comparison test, $\mathrm{P}=0.0301$ ). In the multiple comparison test, although the $\mathrm{CD} 44^{+} \mathrm{CD} 24^{-/ \text {low }}$ subtype did not reveal distinct characteristics in age and tumor size when separately compared with the $\mathrm{BL}$ group and $\mathrm{AR}^{+}$group, the percentage of patients older than 50 years $(53.8 \%)$ and the percentage of pT1 tumors (46.2\%) were intermediate between the BL group and $\mathrm{AR}^{+}$group.

As for the Ki67 labeling index, multiple comparison revealed that a significant difference existed between AR+ group and $\mathrm{BL}$ group $(\mathrm{P}<0.001)$, and also between $\mathrm{AR}^{+}$group and $\mathrm{CD} 44^{+} \mathrm{CD} 24^{-/ \text {low }}$ group $(\mathrm{P}=0.0389)$. However, $\mathrm{BL}$ group and $\mathrm{CD} 44^{+} \mathrm{CD} 24^{- \text {low }}$ group did not differ in $\mathrm{Ki} 67(\mathrm{P}=0.1463)$. A total of $22.2 \%$ of $\mathrm{AR}^{+}$tumors had a Ki67 labeling index
$>30 \%$, which indicated a less proliferative subtype compared with the BL group $(65.1 \%)$ and $\mathrm{CD} 44^{+} \mathrm{CD} 24^{-/ \text {low }}$ subtype $(51.3 \%)$.

RFS and BCSS by IHC subtypes. The RFS time of TNBC patients ranged from 4 to 102 months with a median time of 61 months. During the study period, 50 out of $154(32.5 \%)$ TNBC patients experienced local recurrence and/or metastasis. Among these 50 cases, 32 (64\%) were in the BL group, $3(6 \%)$ were in the $\mathrm{AR}^{+}$group, $13(26 \%)$ were in the $\mathrm{CD} 44^{+} \mathrm{CD} 24^{-/ \text {low }}$ subtype, and $2(4 \%)$ were in the unclassified group. The hazard ratio (HR) and 95\% confidence interval (CI) of RFS for several basic characteristics by TNBC subtype are shown in Table III. Survival analyses are demonstrated in Fig. 3A. Larger tumor size, positive lymph node status and higher histological grade significantly increased the recurrence risk of TNBC tumors. All of the three subgroups maintained this feature of TNBCs. However, marked tumor necrosis, which could increase the recurrence risk of TNBC, $\mathrm{AR}^{+}$and $\mathrm{CD} 44^{+} \mathrm{CD} 24^{-/ \text {low }}$ subgroups, did not significantly affect the RFS within the BL subgroup. A higher Ki67 labeling index $(>30 \%)$ only increased the recurrence risk of $\mathrm{AR}^{+}$tumors.

The BCSS time ranged from 2 to 108 months with a median time of 68 months. Thirty-six of the $154(23.4 \%)$ 
Table II. Clinicopathological characteristics of triple-negative breast cancer immunohistochemical subtypes.

\begin{tabular}{lccc}
\hline Characteristics & $\begin{array}{c}\text { Basal-like } \\
\mathrm{n}=83\end{array}$ & $\begin{array}{c}\mathrm{AR}^{+} \\
\mathrm{n}=18\end{array}$ & $\begin{array}{c}\mathrm{CD}^{+} \mathrm{CD} 24^{-/ \text {low }} \\
\mathrm{n}=39\end{array}$ \\
\hline $\begin{array}{l}\text { Age } \\
\leq 50\end{array}$ & 52 & $6^{\mathrm{a}}$ & 0.038 \\
$>0$ & 31 & 12 & 21
\end{tabular}

Family history of

breast cancer

No

Yes

Histological type

Invasive ductal carcinoma

\section{3}

Invasive lobular carcinoma

Medullary carcinoma

Metaplastic carcinoma

Apocrine carcinoma

Others

Pathological tumor size

pT1

pT2-3

Histological grade

1

2

3

Pathological axillary

lymph node status

Negative

Positive

Lymphovascular invasion

\section{Absent}

Present

Necrosis

Minimal or absent

Marked

Ki67

$\leq 30 \%$

$<30 \%$

EGFR

Negative

Positive

E-cadherin

Negative

Positive

Vimentin

Negative

Positive

Claudin 3

Negative

Positive

Claudin 4

Negative

Positive
12

6

16

2

$16^{\mathrm{a}, \mathrm{b}}$

2

$14^{\mathrm{a}, \mathrm{b}}$

$$
4
$$

8

6

4

14

15

3

2

16

1

17
35

4

14

1

2

19

0

3

18

21

$7^{\mathrm{a}, \mathrm{b}}$

11

21

23

16

26

13

$24^{\mathrm{a}, \mathrm{b}}$

15

$19^{\mathrm{a}, \mathrm{b}}$

20

$30^{\mathrm{a}, \mathrm{b}}$

9

$37^{\mathrm{a}, \mathrm{b}}$

2

$4^{\mathrm{a}, \mathrm{b}}$

35

$36^{\mathrm{a}, \mathrm{b}}$

3

$29^{\mathrm{a}, \mathrm{b}}$

10
0.734

0.003

0.041

$<0.001$

$<0.001$

0.006

$<0.001$

$<0.001$

$<0.001$

$<0.001$ 
Table II. Continued.

\begin{tabular}{|c|c|c|c|c|}
\hline Characteristics & $\begin{array}{l}\text { Basal-like } \\
n=83\end{array}$ & $\begin{array}{l}\mathrm{AR}^{+} \\
\mathrm{n}=18\end{array}$ & $\begin{array}{c}\mathrm{CD} 44^{+} \mathrm{CD} 24^{-/ \text {low }} \\
\mathrm{n}=39\end{array}$ & P-value \\
\hline Claudin 7 & & & & $<0.001$ \\
\hline Negative & 11 & 1 & $28^{\mathrm{a}, \mathrm{b}}$ & \\
\hline Positive & 72 & 17 & 11 & \\
\hline Chemotherapy & & & & 0.512 \\
\hline No & 14 & 4 & 10 & \\
\hline Yes & 69 & 14 & 29 & \\
\hline \multicolumn{5}{|l|}{ RFS event } \\
\hline No & 51 & 15 & 26 & \\
\hline Yes & 32 & 3 & 13 & \\
\hline $\begin{array}{l}\text { Mean survival time } \\
(95 \% \mathrm{CI})\end{array}$ & $\begin{array}{c}75.8 \\
(59.9-88.4)\end{array}$ & $\begin{array}{c}96.3 \\
(84.0-105.7)\end{array}$ & $\begin{array}{c}84.7 \\
(73.4-94.2)\end{array}$ & \\
\hline
\end{tabular}

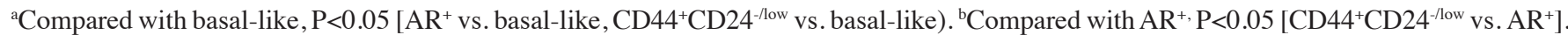
$\mathrm{AR}$, androgen receptor; EGFR, epidermal growth factor receptor; RFS, relapse free survival; CI, confidence interval.

TNBC patients succumbed to breast cancer, 12 patients succumbed to other diseases and 106 were alive at the end of the study. The HR and $95 \%$ CI for BCSS are shown in Table IV, and survival analyses are shown in Fig. 3B. The three subtypes did not exhibit notable differences either in the RFS or BCSS time (log-rank $\mathrm{P}=0.053$ for RFS, log-rank $\mathrm{P}=0.126$ for BCSS). Multiple comparison only detected a difference between the $\mathrm{AR}^{+}$and $\mathrm{BL}$ group (log-rank $\mathrm{P}=0.020$ for RFS, $\log$-rank $\mathrm{P}=0.044$ for $\mathrm{BCSS}$ ). Tumor size, lymph node involvement, histological grade and tumor necrosis were significant prognostic factors in the analysis with all cases of TNBC, and with each subtype of TNBC. In the $\mathrm{AR}^{+}$group, a higher Ki67 labeling index $(>30 \%)$ also demonstrated prognostic value.

Chemotherapy effects on the subtypes. The univariate analyses above tested the prognostic value of adjuvant chemotherapy in all TNBC cases and the different subcategories, and it was revealed that only the BL group received a significant RFS and BCSS benefit from adjuvant chemotherapy (RFS: HR, 0.26; 95\% CI, 0.12-0.71; P=0.004; BCSS: HR, 0.18; 95\% CI, 0.09-0.65; $\mathrm{P}<0.001)$, whereas adjuvant chemotherapy was not associated with significantly prolonged RFS and BCSS in other subtypes and TNBCs as a whole. In order to investigate whether the three subtypes responded differently to chemotherapy, we further divided each subtype into two groups in the survival analysis depending on use of adjuvant chemotherapy. Among the $83 \mathrm{BL}$ patients, 31 were treated with anthracycline-based chemotherapy (19 with doxorubicin/cyclophophamide and 12 with fluorouracil/doxorubicin/cyclophosphamide), 38 were treated with nonanthracycline-based chemotherapy (cyclophosphamide, methotrexate and fluorouracil), and 14 received no adjuvant systemic therapy. Among the $18 \mathrm{AR}^{+}$ patients, 9 received anthracycline-based chemotherapy (3 doxorubicin/cyclophosphamide and 6 fluorouracil/doxorubicin/cyclophosphamide), 5 received nonanthracycline-based chemotherapy, and 4 received no adjuvant systemic therapy. Among the $39 \mathrm{CD} 44^{+} \mathrm{CD} 24^{-/ \text {low }}$ patients, 21 received anthracycline-based chemotherapy (14 doxorubicin/cyclophosphamide and 7 fluorouracil/doxorubicin/cyclophosphamide), 8 received nonanthracycline-based chemotherapy, and 10 received no adjuvant systemic therapy.

The survival analysis revealed that patients in the BL group without chemotherapy had the shortest RFS and BCSS times and demonstrated a significant survival gain following chemotherapy $(\mathrm{P}=0.003$ for $\mathrm{RFS}, \mathrm{P}<0.001$ for $\mathrm{BCSS}$; Fig. 3C-F). Conversely, $\mathrm{AR}^{+}$and $\mathrm{CD} 44^{+} \mathrm{CD} 24^{-/ \text {low }}$ patients did not demonstrate a chemotherapy benefit in either RFS or BCSS. However, the results require careful interpretation due to the small numbers. There was no difference in RFS and BCSS among the three subclasses; however, after we categorized each subclass according to chemotherapy, a notable distinction emerged (log-rank $\mathrm{P}=0.003$ for RFS, log-rank $\mathrm{P}=0.008$ for BCSS).

In the multiple variate analyses (adjusted for age, tumor size, histological grade, lymph node status and tumor necrosis), the BL group demonstrated a significantly poorer survival, with a HR of 2.98 vs. the luminal A cohort (95\% CI, 1.38-6.10; $\mathrm{P}<0.001$; Table VA), a higher HR of 3.81 vs. luminal $\mathrm{A}$ in the cases without chemotherapy (95\% CI, 1.98-6.32; $\mathrm{P}<0.001$; Table VC), and a relatively lower HR of 1.93 vs. luminal A in the cases with chemotherapy $(95 \% \mathrm{CI}, 1.21-4.09, \mathrm{P}=0.028$; Table VB). This confirmed the survival gain of adjuvant chemotherapy in $\mathrm{BL}$ patients. In contrast, the $\mathrm{AR}^{+}$group did not exhibit a poorer survival vs. the luminal A cohort (HR, 1.38; 95\% CI, 0.67-2.14; $\mathrm{P}=0.204$ ), and the HR was 1.13 (95\% CI, 0.62-2.89; $\mathrm{P}=0.574)$ in the cases with chemotherapy, and 1.53 (95\% CI, 0.68-1.98; $\mathrm{P}=0.124)$ in the cases without chemotherapy. The decrease in HR owing to chemotherapy in the $\mathrm{AR}^{+}$group (from 1.53 to 1.13 ) was far less significant than that in the BL group (from 3.81 to 1.93 ). In the $\mathrm{CD} 44^{+} \mathrm{CD} 24^{- \text {/low }}$ group, there was an increase rather than a decrease in HR in the subset of patients who received chemotherapy (HR, 2.30; $95 \%$ CI, 0.95-2.84; $\mathrm{P}=0.003$ ) compared with those who did not (HR, 1.72; 95\% CI, 0.88-2.74; P=0.092). We cannot 

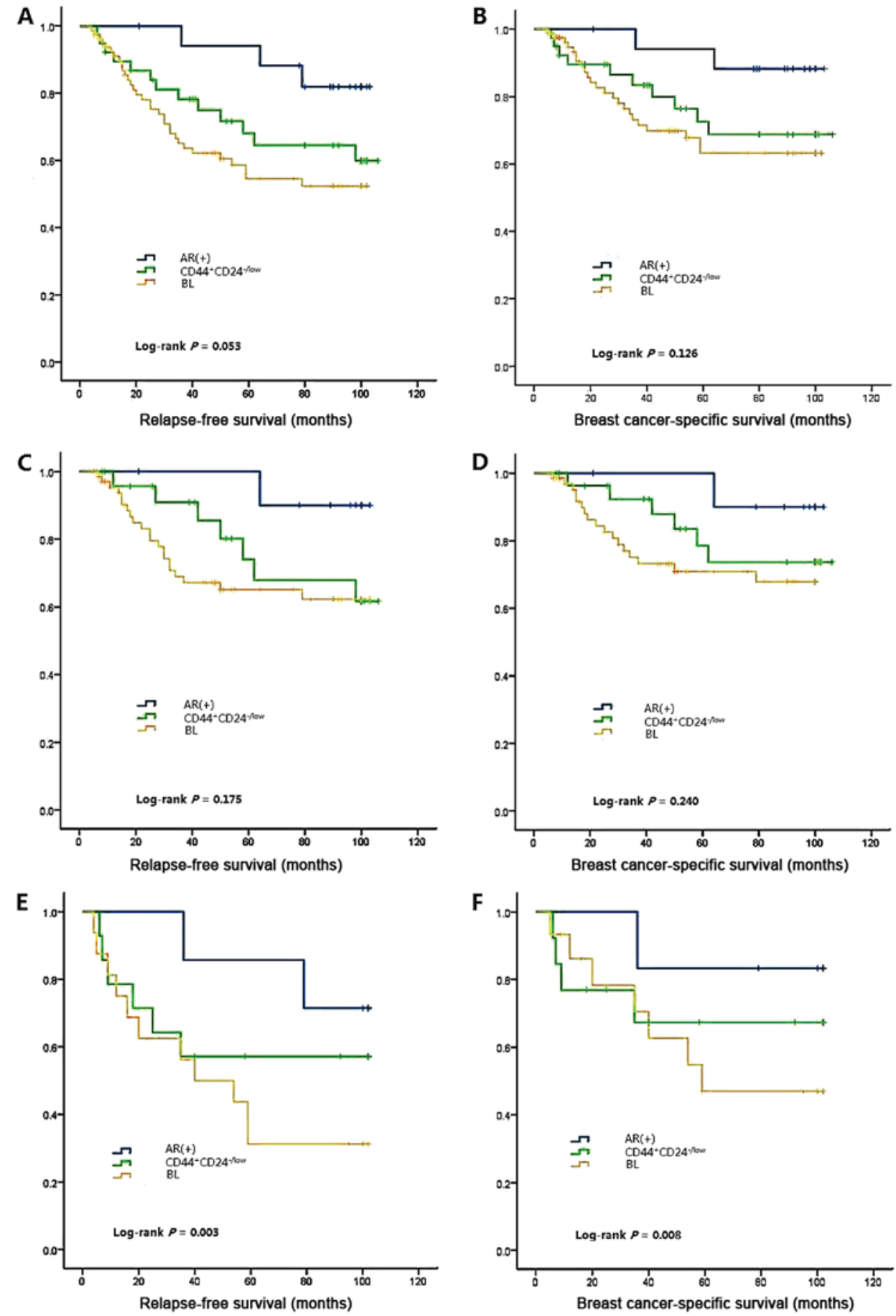

Figure 3. Kaplan-Meier curves of relapse-free and breast cancer-specific survival. (A,C,E) Relapse-free survival according to three immunohistochemistry-based subtypes of triple-negative breast cancer. (B, D and E) Breast cancer-specific survival according to three immunohistochemistry-based subtypes of triple-negative breast cancer. (A and B) all cases combined; (C and D) Cases receiving chemotherapy; (E and F) cases without chemotherapy. AR, androgen receptor; BL, basal-like.

assume that chemotherapy increases the risk of mortality in $\mathrm{CD} 44^{+} \mathrm{CD} 24^{- \text {llow }}$ phenotype TNBCs, but the results did reveal a notable trait of $\mathrm{CD} 44^{+} \mathrm{CD} 24^{- \text {/low }}$ tumors in that they do not respond to chemotherapy as well as the BL subtype.

Correlation between IHC TNBC subtypes and subtypes in non-TNBC. CK5 $/ 6^{+}, \mathrm{CK} 14^{+}$and $\mathrm{CD} 44^{+} \mathrm{CD} 24^{-/ l o w}$ phenotype were not only observed in TNBCs, but also in non-TNBC cases. Of the 1492 non-TNBCs, 34 cases positively expressed either CK5/6 or CK14, and they are referred to as BL/non-TN in this study. Accordingly, the 36 cases that had the $\mathrm{CD} 44^{+} \mathrm{CD} 24^{- \text {llow }}$ phenotype are referred to as $\mathrm{CD} 44^{+} \mathrm{CD} 24^{-/ \mathrm{low}} / \mathrm{non}-\mathrm{TN}$. An issue that cannot be ignored is the correlation between $\mathrm{BL}$ tumors that are TNBC (BL/TN) and $\mathrm{BL} /$ non-TN, and $\mathrm{CD} 44^{+} \mathrm{CD} 24^{- \text {-low }}$ tumors that are $\mathrm{TNBC}$ $\left(\mathrm{CD} 44^{+} \mathrm{CD} 24^{-/ \text {low }} / \mathrm{TN}\right)$ and $\mathrm{CD} 44^{+} \mathrm{CD} 24^{-/ \text {low }} /$ non-TN. To be specific, we take the BL subtype as an example. BL was defined as positive for CK5/6 or CK14, and BL/TN has certain distinct features as shown above, including younger age, higher histological grade and poorer prognosis. Therefore, 


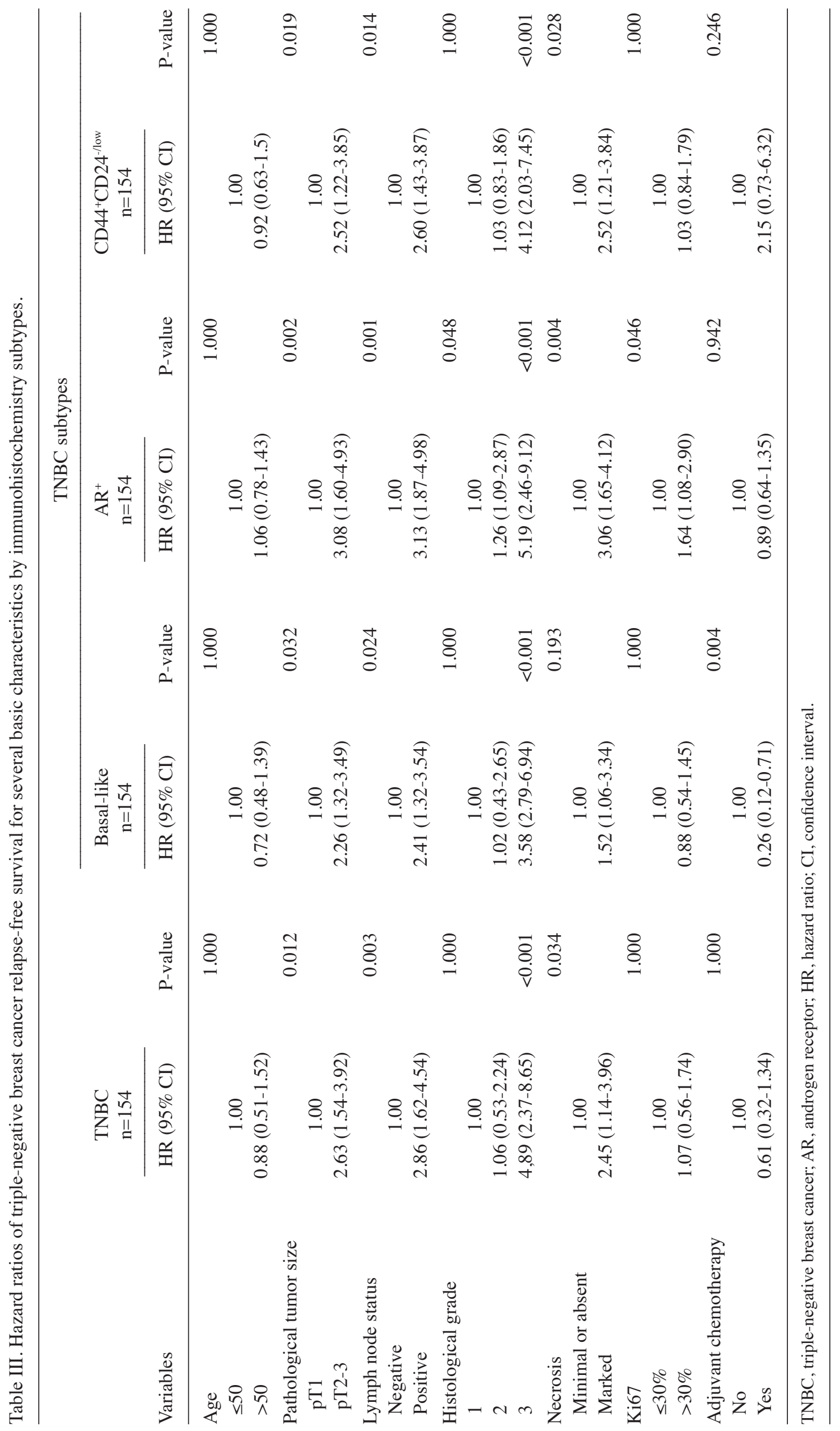




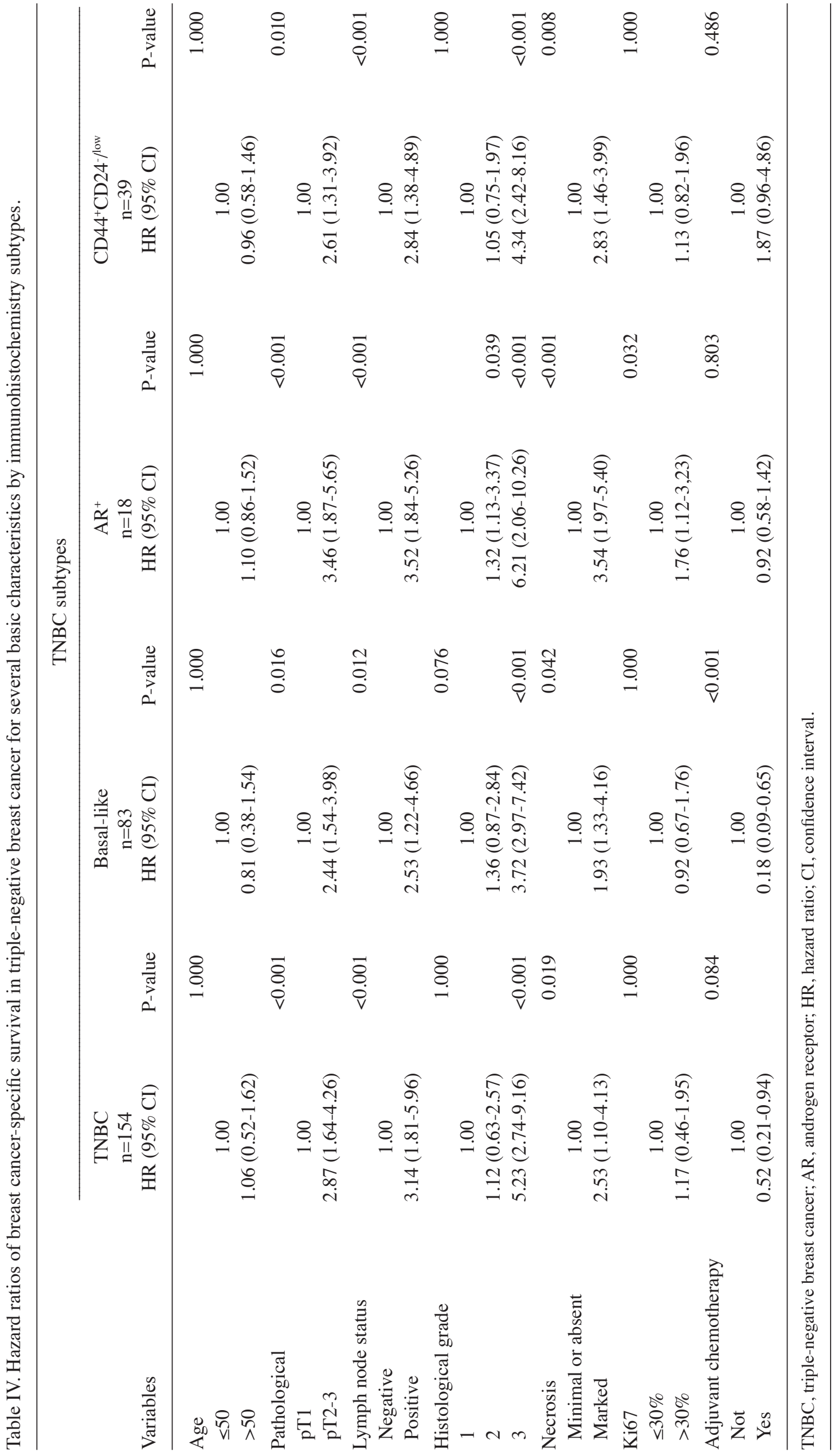


Table V. Cox regression analysis to estimate adjusted hazard ratios of breast cancer subtypes.

A, Cox regression analysis of all 1646 cases

\begin{tabular}{|c|c|c|c|c|}
\hline \multirow[b]{2}{*}{ Subtypes } & \multicolumn{2}{|c|}{ Relapse-free survival } & \multicolumn{2}{|c|}{ Breast cancer-specific survival } \\
\hline & HR $(95 \% \mathrm{CI})$ & P-value & HR $(95 \%$ CI $)$ & $\mathrm{P}$-value \\
\hline IHC-Luminal A & 1.00 & & 1.00 & \\
\hline IHC-HER2 & $2.96(1.23-4.87)$ & $<0.001$ & $3.13(2.28-5.07)$ & $<0.001$ \\
\hline IHC-TNBC & $2.04(1.11-4.38)$ & 0.017 & $2.15(1.43-4.16)$ & 0.008 \\
\hline IHC-TN/BL & $2.85(1.18-5.02)$ & $<0.001$ & $2.98(1.38-6.10)$ & $<0.001$ \\
\hline IHC-TN/AR ${ }^{+}$ & $1.12(0.87-1.68)$ & 0.541 & $1.38(0.67-2.14)$ & 0.204 \\
\hline IHC-TN/CD $44^{+} \mathrm{CD} 24^{-/ \text {low }}$ & $1.78(1.07-3.20)$ & 0.073 & $1.86(1.18-3.75)$ & 0.052 \\
\hline IHC-TN/unassigned & $1.26(1.11-2.45)$ & 0.296 & $1.43(1.06-2.82)$ & 0.187 \\
\hline
\end{tabular}

B, Cox regression analysis of 1360 cases treated with adjuvant chemotherapy

\begin{tabular}{|c|c|c|c|c|}
\hline \multirow[b]{2}{*}{ Subtypes } & \multicolumn{2}{|c|}{ Relapse-free survival } & \multicolumn{2}{|c|}{ Breast cancer-specific survival } \\
\hline & HR $(95 \%$ CI) & $\mathrm{P}$-value & HR (95\% CI) & $\mathrm{P}$-value \\
\hline IHC-Luminal A & 1.00 & & 1.00 & \\
\hline IHC-HER2 & $2.61(1.24-4.78)$ & $<0.001$ & $2.72(1.52-5.12)$ & $<0.001$ \\
\hline IHC-TNBC & $1.93(1.13-3.34)$ & 0.031 & $2.11(1.28-3.84)$ & 0.019 \\
\hline IHC-TN/BL & $1.89(1.17-3.96)$ & 0.048 & $1.93(1.21-4.09)$ & 0.028 \\
\hline IHC-TN/AR ${ }^{+}$ & $1.09(0.45-1.56)$ & 0.622 & $1.13(0.62-2.89)$ & 0.574 \\
\hline IHC-TN/CD $44^{+} \mathrm{CD} 24^{-/ \text {low }}$ & $2.17(0.76-2.74)$ & 0.006 & $2.30(0.95-2.84)$ & 0.003 \\
\hline IHC-TN/unassigned & $1.14(0.45-2.35)$ & 0.507 & $1.31(0.61-2.72)$ & 0.232 \\
\hline
\end{tabular}

C, Cox regression analysis of 286 cases treated without chemotherapy

\begin{tabular}{|c|c|c|c|c|}
\hline \multirow[b]{2}{*}{ Subtypes } & \multicolumn{2}{|c|}{ Relapse-free survival } & \multicolumn{2}{|c|}{ Breast cancer-specific survival } \\
\hline & HR $(95 \% \mathrm{CI})$ & $\mathrm{P}$-value & HR $(95 \% \mathrm{CI})$ & P-value \\
\hline IHC-Luminal A & 1.00 & & 1.00 & \\
\hline IHC-HER2 & $3.32(1.32-5.14)$ & $<0.001$ & $3.48(1.15-5.54)$ & $<0.001$ \\
\hline IHC-TNBC & $2.19(1.11-4.98)$ & 0.002 & $2.25(1.08-5.11)$ & $<0.001$ \\
\hline IHC-TN/BL & $3.64(1.86-7.65)$ & $<0.001$ & $3.81(1.98-6.32)$ & $<0.001$ \\
\hline IHC-TN/AR ${ }^{+}$ & $1.25(0.76-2.24)$ & 0.287 & $1.53(0.68-1.98)$ & 0.124 \\
\hline IHC-TN/CD $44^{+} \mathrm{CD} 24^{- \text {-low }}$ & $1.68(1.14-3.07)$ & 0.115 & $1.72(0.88-2.74)$ & 0.092 \\
\hline IHC-TN/unassigned & $1.37(0.64-2.73)$ & 0.196 & $1.48(0.49-2.64)$ & 0.163 \\
\hline
\end{tabular}

HR, hazard ratio; CI, confidence interval; IHC, immunohistochemistry; HER2, human epidermal growth factor-2; TNBC, triple-negative breast cancer; BL, basal-like; AR, androgen receptor.

through a comparison of clinicopathological characteristics between $\mathrm{BL} / \mathrm{TN}$ and BL/non-TN we could observe whether these features of $\mathrm{CK} 5 / 6^{+}$and/or $\mathrm{CK} 14^{+}$tumors would be retained regardless of their clinical ER, PR and HER2 status, and particularly their TN status. The results of comparison may indicate whether BL/TN cases possess these traits more due to their BL status (i.e. their positivity for CK5/6 or CK14) or more due to their TN status (i.e. their triple-negative status). Thus, it may provide us with a better understanding of the intrinsic quality of these TNBC subtypes. A comparison of clinicopathological characteristics between $\mathrm{BL} / \mathrm{TN}$ and $\mathrm{BL} /$ non-TN, and $\mathrm{CD} 44^{+} \mathrm{CD} 24^{-/ \mathrm{low}} / \mathrm{TN}$ and CD $44^{+} \mathrm{CD} 24^{-/ \text {low }} /$ non-TN is shown in Table V. As for the $\mathrm{AR}^{+}$ group, we did not compare $\mathrm{AR}^{+}$tumors that were triple-negative with those that were not. As mentioned in the Patients and methods section, several previous studies $(10,13,20,21)$ have made the same observation that TN tumors with high AR protein and/or gene expression (or LAR, according to Lehmann et al $(10,12)$ were usually identified as HER2 or luminal by PAM50 intrinsic subtyping, and their levels of AR 


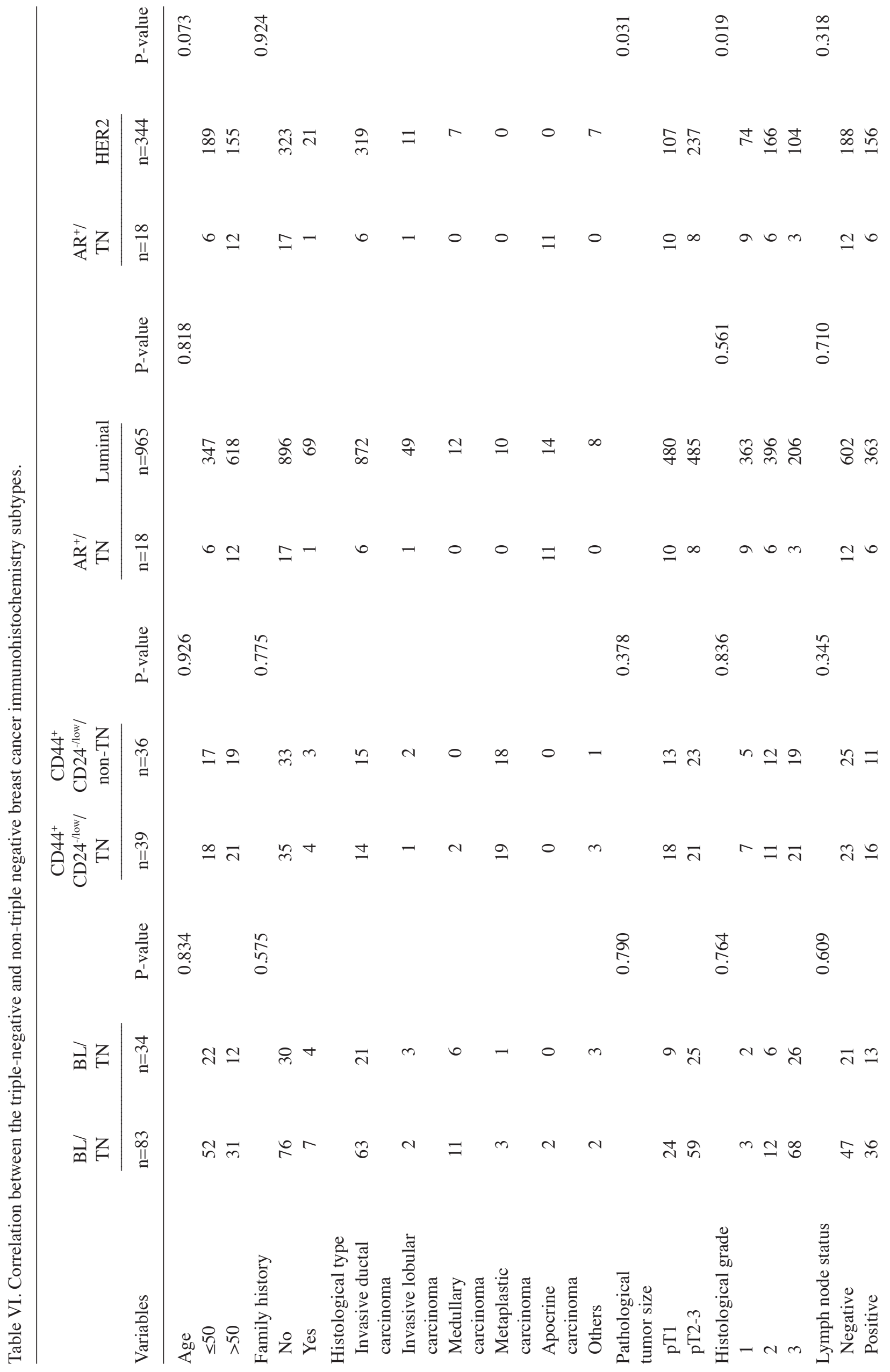




\begin{tabular}{|c|c|c|c|c|c|c|c|c|c|c|c|c|c|c|c|c|c|}
\hline & 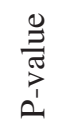 & $\begin{array}{l}\infty \\
\infty \\
0 \\
0\end{array}$ & & $\frac{\text { Ig }}{3}$ & & ষ্ & & $\begin{array}{l}\overrightarrow{8} \\
\dot{0} \\
\dot{v}\end{array}$ & & ஓे & & $\underset{f}{\stackrel{f}{f}}$ & $\begin{array}{l}\infty \\
\infty \\
0\end{array}$ & & $\begin{array}{l}0 \\
\text { to } \\
0 \\
0\end{array}$ & & $\begin{array}{c}\infty \\
\stackrel{5}{0} \\
0\end{array}$ \\
\hline $\begin{array}{l}\frac{2}{11} \\
\underline{y}\end{array}$ & 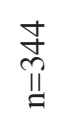 & & ஓे ซ & & ঠે & & 守 $\cong$ & & $\underset{\sim}{\infty}$ & & 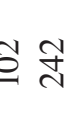 & 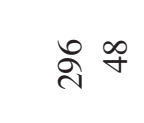 & & हे & & 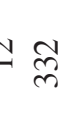 & a m \\
\hline 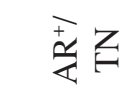 & $\stackrel{\infty}{\stackrel{\infty}{=}}$ & & $\varrho \sim$ & & $\simeq m$ & & $\pm ナ$ & & $\infty \subseteq$ & & + \pm & $\cong m$ & & $v \underline{0}$ & & -1 & -1 \\
\hline & 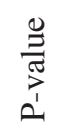 & 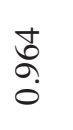 & & $\stackrel{\stackrel{t}{+}}{\stackrel{0}{0}}$ & & $\stackrel{\infty}{+\infty}$ & & $\stackrel{\vec{\circ}}{\circ}$ & & $\overrightarrow{\widetilde{\sigma}}$ & & ڤั้ & 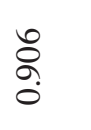 & & $\begin{array}{l}\text { fै } \\
\stackrel{0}{0}\end{array}$ & & 홍 \\
\hline 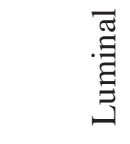 & $\begin{array}{l}\text { ஜb } \\
\text { II } \\
=\end{array}$ & & $\vec{\infty} \stackrel{+}{0}$ & & 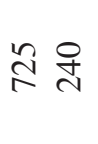 & & $\underset{\infty}{\infty} \underset{\sim}{\infty}$ & & $\frac{n}{f} \tilde{g}$ & & है § & 苔 $\overline{\mathrm{v}}$ & & : & & $\hat{0} \underset{\infty}{0}$ & $\vDash \underset{\infty}{+}$ \\
\hline 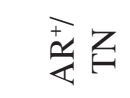 & $\stackrel{\infty}{\stackrel{\infty}{I}}$ & & $\stackrel{\circ}{=}$ & & $\approx m$ & & $\pm ナ$ & & $\infty \subseteq$ & & + \pm & $\simeq m$ & & 10 & & -1 & -1 \\
\hline & 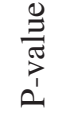 & $\stackrel{\infty}{\stackrel{\infty}{2}}$ & & $\begin{array}{l}\stackrel{\infty}{0} \\
0 \\
0\end{array}$ & & $\underset{\nabla}{\overrightarrow{0}}$ & & $\stackrel{\bar{Q}}{\circ}$ & & $\frac{\Omega}{0}$ & & $\begin{array}{l}\overrightarrow{0} \\
\stackrel{1}{0}\end{array}$ & $\vec{\sigma}$ & & \begin{tabular}{l}
\multirow{2}{*}{} \\
$\infty$ \\
0 \\
0
\end{tabular} & & ్ֶָ \\
\hline 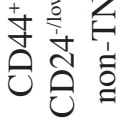 & II & & $\vec{\sim} \bumpeq$ & & $\approx \pm$ & & 유 & & ì & & $\vec{m} n$ & $-\stackrel{\mathrm{\lambda}}{ }$ & & 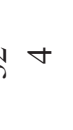 & & 0 & \& \\
\hline 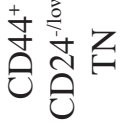 & $\stackrel{\text { II }}{=}$ & & $\stackrel{\sim}{2}$ & & $\approx I$ & & ๑ તి & & p a & & $n d$ & $\nabla n$ & i & $r^{n}$ & 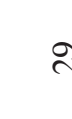 & i응 & $\stackrel{\sim}{)}=$ \\
\hline & 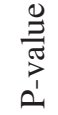 & $\begin{array}{l}\frac{1}{\infty} \\
0 \\
0\end{array}$ & & $\begin{array}{l}n \\
n \\
n\end{array}$ & & 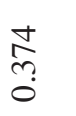 & & 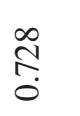 & & 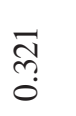 & & $\begin{array}{l}\stackrel{0}{0} \\
0 \\
0\end{array}$ & $\stackrel{\infty}{=}$ & & $\frac{\infty}{m}$ & & $\begin{array}{c}\widehat{c} \\
\infty \\
0 \\
0\end{array}$ \\
\hline 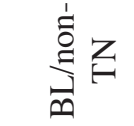 & $\stackrel{+}{\stackrel{I}{=}}$ & & $\ddot{\sim} \sigma$ & & 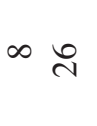 & & $a \sqrt{2}$ & & $\infty \simeq$ & & $a$ & 긍 & $\infty$ & o & & $\stackrel{\infty}{\sim}$ & $\forall$ ల \\
\hline$\vec{\nexists}$ & $\stackrel{\infty}{\Perp}$ & & $\widehat{6}$ त & & ఫ̊ î & & તે it & & $\forall \mathcal{F}$ & & $\infty$ & $i n$ & & $m$ & & 文 & $=\mathbb{N}$ \\
\hline & $\frac{0}{0}$ & 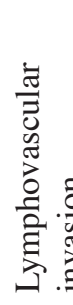 & 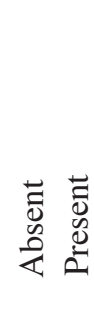 & $\begin{array}{l}\frac{n}{0} \\
\stackrel{0}{0} \\
0\end{array}$ & 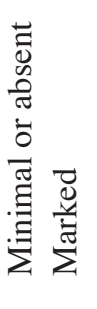 & $\widehat{n}$ & 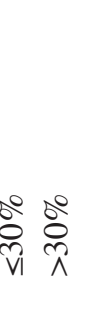 & 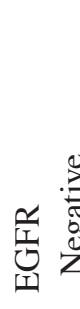 & 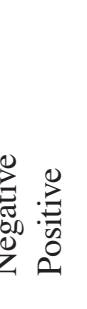 & 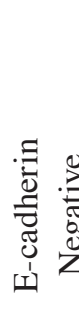 & 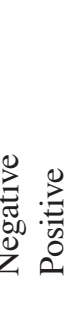 & 䍖离 & 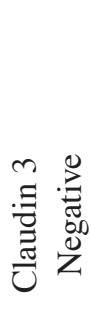 &.$\overbrace{0}^{0}$ & 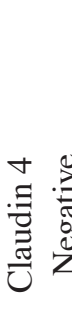 & $\sum_{0}^{\infty}$ & 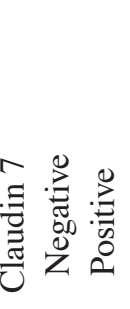 \\
\hline
\end{tabular}


expression resembled the levels observed in HER2 and ER-positive tumors that were not TN. However, the authors had divergent opinions on percentage that the HER2 and luminal groups accounted for. According to Mayer et al (19), the LAR subtype is classified as HER2 (74.3\%) and luminal (14.3\%); however, based on the statistics of Lehmann et al (10) $82 \%$ of LAR cases were luminal (either luminal A or B). Therefore, we separately compared the $\mathrm{AR}^{+}$group of TNBC with

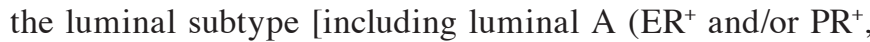
HER 2 ${ }^{-}$) and luminal $\mathrm{B}\left(\mathrm{ER}^{+}\right.$and/or $\left.\mathrm{PR}^{+}, \mathrm{HER} 2^{+}\right)$] and HER2 subtype (ER', PR- HER $\left.2^{+}\right)$that were not TNBC. Based on the data from Table VI, BL/TN cases demonstrated almost undistinguishable clinicopathological characteristics compared with $\mathrm{BL} /$ non-TN cases, as did $\mathrm{CD} 44^{+} \mathrm{CD} 24^{-/ \text {low }} / \mathrm{TN}$ cases compared with $\mathrm{CD} 44^{+} \mathrm{CD} 24^{-/ \text {low/non-TN }}$ cases. The features of the $\mathrm{AR}^{+}$group resembled those of the non-TNBC luminal group rather than those of HER2. Next, a survival analysis was performed and differences in RFS and BCSS were compared between BL/TN and BL/non-TN, CD44 ${ }^{+} \mathrm{CD} 24^{- \text {-low }} / \mathrm{TN}$ and

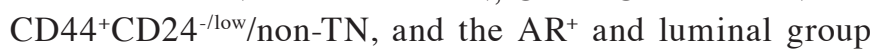
(Fig. 4). Multiple comparison revealed no significant difference between $\mathrm{BL} / \mathrm{TN}$ and $\mathrm{BL} / \mathrm{non}-\mathrm{TN}$ (log-rank $\mathrm{P}=0.9$ for RFS, log-rank $\mathrm{P}=0.9$ for BCSS), $\mathrm{CD} 44^{+} \mathrm{CD} 24^{- \text {llow }} / \mathrm{TN}$ and $\mathrm{CD} 44^{+} \mathrm{CD} 24^{-/ \text {low }} /$ non-TN (log-rank $\mathrm{P}=0.6$ for RFS, log-rank $\mathrm{P}=0.5$ for $\mathrm{BCSS}$ ), or the $\mathrm{AR}^{+}$group and luminal group (log-rank $\mathrm{P}=0.7$ for RFS, log-rank $\mathrm{P}=0.8$ for BCSS).

\section{Discussion}

In this study, a large number of clinical breast cancer cases were evaluated and the following observations concerning TN breast cancers were made: i) $\mathrm{TN}$ disease is a heterogeneous clinical entity composed of three main IHC subtypes, with the BL tumor type predominating (>50\%); ii) The three subcategories demonstrated a statistically significant difference with regard to age, tumor size, histological grade, tumor necrosis, Ki67 labeling index and response to chemotherapy; iii) Basal-like tumors that are TN exhibit almost undistinguishable clinicopathological characteristics compared with BL tumors that are non-TN. The same applies with $\mathrm{CD} 44^{+} \mathrm{CD} 24^{-/ l o w} / \mathrm{TN}$ vs. $\mathrm{CD} 44^{+} \mathrm{CD} 24^{-/ \text {low }} /$ non-TN and $\mathrm{AR}^{+} / \mathrm{TN}$ vs. luminal/non-TN.

Our study is a preliminary attempt to use gene expression subtypes in a practical and clinically accessible diagnostic test. We use IHC methodology to observe how TNBC can be broken down into components. This novel IHC classification system was based on the perspectives of Lehmann et al $(10,12,19)$, who identified six subtypes (BL1, BL2, IM, M, MSL and LAR), and Prat et al (13), who contended that the three main subtypes were BL, claudin-low and luminal/HER2-enriched. These two seemingly different classifications are correlated; for instance, LAR shares a number of gene expression features of luminal and HER2-enriched cancers, as illustrated in Patients and methods. However, in the definition of Prat et al (13), the identification of luminal/TN tumors, HER2/TN tumors might appear at first glance to be counterintuitive, and an explanation is required with regard to the discrepancy between gene expression and IHC-based assays. One possibility is the false positivity or false negativity of the IHC-based assays in determining hormone receptor or HER2 status (28). Another possibility is that the pathology and gene expression data 

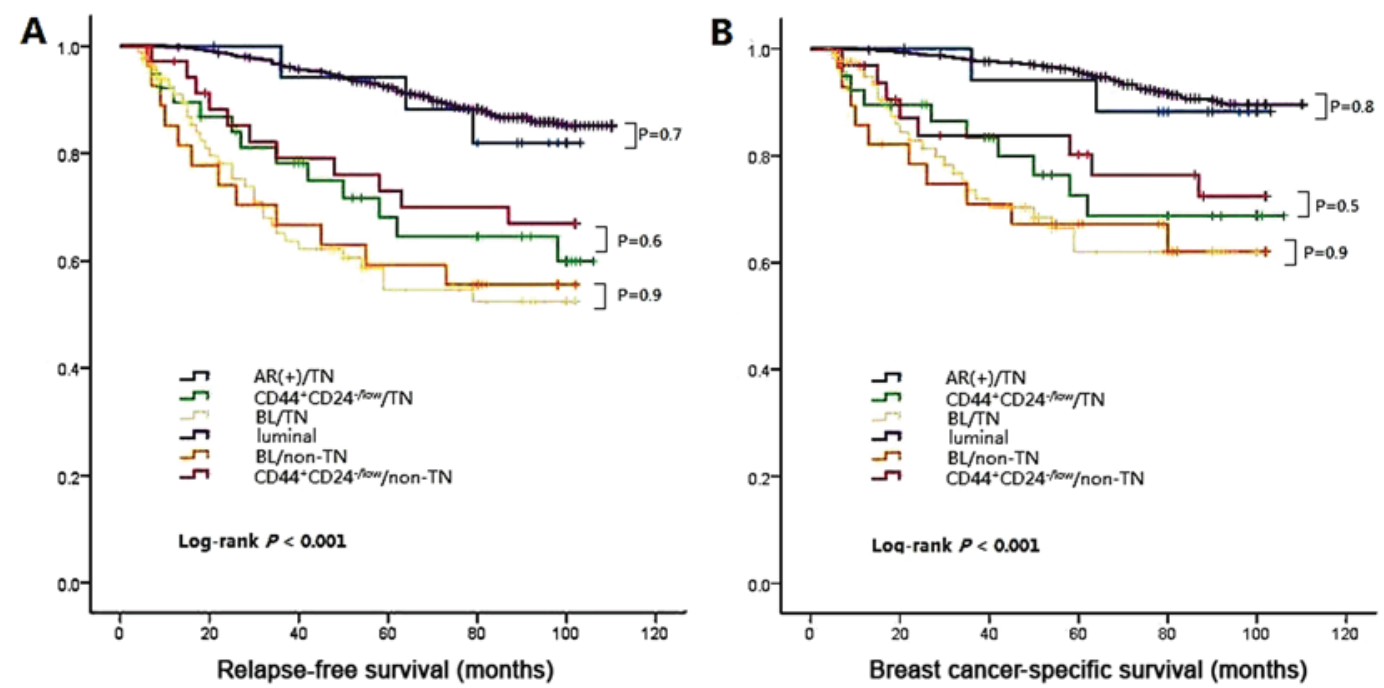

Figure 4. Comparison of relapse-free survival and breast cancer-specific survival between triple-negative (TN) subtypes and non-TN breast cancer subtypes. (A) Relapse-free survival of TN and non-TN subtypes (B). Breast cancer-specific survival in TN and non-TN subtypes. AR, androgen receptor; BL, basal-like.

could have been obtained from two different areas of the same tumor (i.e., intratumor heterogeneity) (29). The most plausible explanation is that gene expression measures a large number of related genes, compared with the three individual pathology-based biomarkers that define TN disease (13). Thus, multigene expression data using tens to hundreds of genes might better capture the true biological profile of a given tumor compared with three or four individual biomarkers (30). For example, a TN tumor that has low levels of ESR1 and PGR, and consequently is ER ${ }^{-}$and PR by IHC, might be identified as luminal due to the high expression of other luminal-related genes (i.e., AR, GATA3 and/or FOXAl) and the low expression of basal- and proliferation-related genes. Another example comes from the identification of HER2-enriched/TN tumors that do not amplify ERBB2, some of which might be driven by high EGFR (13).

In previous studies, BL breast cancers accounted for up to $15 \%$ of all breast cancers $(31,32)$. Most of them used the definition of Nielsen et al (31), which is positive staining for CK5/6 or EGFR (31). In this study, the proportion of BL breast cancers was $7.11 \%$ (53.9\% of TNBCs). Of a total of $117 \mathrm{BL}$ breast cancers, $70.94 \%$ (83 of 117) were TNBCs, and $29.06 \%$ (34 of 117) were non-TNBCs. We used basal markers CK5/6 and CK14 instead of CK5/6 and EGFR for four reasons: i) Based on the recent progress in TNBC gene subtyping by Prat et al (13), expression of EGFR was observed to be significantly increased in HER2-enriched/TN tumors compared with HER2-enriched/non-TN tumors, thus suggesting that certain HER2-enriched tumors, which are at gene level in line with HER2-enriched tumors but are HER2- by IHC, may be driven by EGFR as discussed above. This implies that EGFR expression is not confined to BL cancers $(10,19)$. ii) The EGFR gene is not enriched in all BL tumors but in the BL2 subtype alone (10). It is also enriched in a minority of mesenchymal subtypes (10). iii) Not only has specificity of EGFR for defining BL breast cancers become lower than it used to be when subtyping was not as comprehensive as today, but also the prognostic value of EGFR was challenged. In the study of Choi et al (33), CK5/6 was a poor prognostic marker whereas
EGFR was not. 4) According to Won et al (34), in a survey of IHC biomarkers for BL breast cancer against a gene expression profile gold standard, CK14 was the most specific (specificity 100\%) among the 46 biomarkers surveyed. If we used CK5/6 and EGFR, the proportion of BL breast cancers increased to $14.12 \%$, and accounted for $65.6 \%$ of TNBCs, which was similar to the figure of $15 \%$ obtained in the previous study. However, this might obscure certain significant information since $\mathrm{EGFR}^{+}$tumors comprise part of the $\mathrm{AR}^{+}$group. Indeed, 10 out of $18 \mathrm{AR}^{+} \mathrm{TNBCs}$ demonstrated weak or strong positivity for EGFR.

$\mathrm{AR}^{+}$tumors constitute a distinct subgroup of TNBC. A total of $11.7 \%$ of TNBCs were $\mathrm{AR}^{+}$in this study. Among 22 studies summarized in the article of Safarpour et al (35), the proportion of tumors with positive AR among TNBCs ranged from $6.6 \%$ to $75 \%$. Among six studies which had used the most recent ASCO/CAP guidelines (1\% and more) for ER, PR and AR positivity, the expression rate of AR ranged from $12.7 \%$ to $41.4 \%$. This group has certain valuable clinicopathological features including smaller tumor size, higher median age, lower histological grade, higher percentage of apocrine morphology, lower proliferation index (measured by Ki67) and statistically longer disease-free survival and overall survival (8,36-48). Our study also arrived at similar conclusions. In terms of IHC features, it is noteworthy that none of the $\mathrm{AR}^{+}$tumors in our study were positive for CK5/6 or CK14, and due to the relatively small series of analyzed samples this may be coincidental; however, it is in accordance with the study of Lehmann et al that LAR cancers lacked expression of basal cytokeratins. So far, no organization has recommended AR assessment for breast cancers; however, we support routine assessment of AR at least for TNBCs considering the predictive value of $A R$ in TNBC.

$\mathrm{AR}^{+}$and $\mathrm{BL}$ are two subtypes that have received significant interest and are relatively well analyzed. However, emerging data imply that TN disease is a broad and diverse category for which additional subclassifications are required. One of the contributions of this study is that, for the first time, we distinguished a subgroup of TNBC as the $\mathrm{CD} 44^{+} \mathrm{CD} 24^{-/ \text {low }}$ 
phenotype using IHC markers, and the overlap between this third group and $\mathrm{BL}$ and $\mathrm{AR}^{+}$was low $(3$ and 0 cases, respectively). CD $44^{+} \mathrm{CD} 24^{-/ \text {low }}$ is a marker of breast stem cells and tumor-initiating cells and is observed to be exclusively enriched in claudin-low subtype $(26,27)$. There are also other features in the claudin-low subtype, for instance, low gene expression of tight junction proteins claudin 3, 4 and 7 and E-cadherin $(9,26,27,49,50)$. However, when we used negativity for claudins 3,4 and 7 to define the third group, there were 24 cases, a relatively large proportion, that could not be classified. This is possibly due to the fact that negativity for all claudins is a much stricter restriction compared with $\mathrm{CD} 44^{+} \mathrm{CD} 24^{-/ \text {low }}$. In addition, a study of Prat et al (9), a researcher who contributed significantly to our knowledge of the claudin-low subtype of breast cancer, revealed that $\mathrm{BL}$ tumors did not demonstrate significantly lower expression of CD24 as a group. This crucial distinction may explain the lowest overlap between the BL group and $\mathrm{CD} 44^{+} \mathrm{CD} 24^{-/ \text {low }}$ group. In another classification where vimentin $^{+}$and E-cadherin- were used, the highest overlap was observed. In fact, undifferentiated levels of mesenchymal (vimentin) markers exist not only within the claudin-low subtype, but also in BL breast cancers, and no statistically significant difference was observed between claudin-low and BL tumors (9). We defined a number of differences between the $\mathrm{CD} 44^{+} \mathrm{CD} 24^{-/ \text {low }}$ subtype and the other groups. Clinicopathological characteristics including histological grade and tumor necrosis were different from the $\mathrm{AR}^{+}$as well as the $\mathrm{BL}$ group. The age at diagnosis of this group was older, the tumor size was smaller, and the Ki67 labeling index was lower than that of the BL group. The two groups demonstrated an unfavorable clinical outcome; however, the $\mathrm{CD} 44^{+} \mathrm{CD} 24^{-/ \text {low }}$ group did not benefit from adjuvant chemotherapy to the extent that the BL group did. Sabatier et al (51) also made similar findings in their study of clinical, pathological and prognostic characterization of claudin-low breast cancers, revealing that the percentage of patients older than 50, the percentage of grade 3 claudin-low tumors, the percentage of tumors measuring $2 \mathrm{~cm}$ or less, and the 5-year disease-free survival rate were all intermediate between that of the highly proliferative subtypes (BL and HER2-enriched) and that of less proliferative ones (luminal A and normal).

Without chemotherapy, the BL subcategory had the poorest prognosis in terms of RFS and BCSS. Notably, the BL group demonstrated a distinct clinical benefit with standard adjuvant chemotherapy. Conversely, adjuvant chemotherapy demonstrated little clinical benefit for the $\mathrm{AR}^{+}$ and $\mathrm{CD} 44^{+} \mathrm{CD} 24^{-/ \text {low }}$ subclasses. Masuda et al (52) performed a retrospective analysis on 130 TNBC cases treated with neoadjuvant adriamycin/cytoxan/taxol-containing chemotherapy, and subtype-specific responses differed substantially, with the BL1 subtype achieving the highest pathological complete remission rate $(52 \%)$, and the BL2, LAR and MSL subtypes having the lowest responses $(0 \%$, $10 \%$ and $23 \%$, respectively). In accordance with the work of Masuda et al (52), Mayer et al (19) observed a similar distribution of subtype-specific differences in survival. These findings should guide differential use of chemotherapy-based regimens and instruct clinical trials to investigate targeted therapies.
In summary, TNBC is a relatively uncommon, notably aggressive disease, and there is a major requirement to better decipher the heterogeneity of TNBC in order to tackle the challenges in combatting this disease. New therapeutic strategies for TNBC are emerging since gene subtyping was identified. Therefore, our future clinical trial design for TNBC intends to focus on continued efforts to translate genetic approaches into clinical utility, to develop a more standard IHC classification of TNBC. Our aim is to provide a labor- and timesaving method for clinicians to distinguish the subtypes of TNBC in their daily work and, in the near future, select a more appropriate personalized therapy based on these subtypes.

\section{Acknowledgements}

This study was supported by the National Natural Science Foundation of China (grant no. 81472343).

\section{References}

1. Cheang MC, Voduc D, Bajdik C, Leung S, McKinney S, Chia SK, Perou CM and Nielsen TO: Basal-like breast cancer defined by five biomarkers has superior prognostic value than triple-negative phenotype. Clin Cancer Res 14: 1368-1376, 2008.

2. Aguiar FN, Mendes HN, Cirqueira CS, Bacchi CE and Carvalho FM: Basal cytokeratin as a potential marker of low risk of invasion in ductal carcinoma in situ. Clinics (Sao Paulo) 68: 638-643, 2013.

3. Fadare O, Wang SA and Hileeto D: The expression of cytokeratin 5/6 in invasive lobular carcinoma of the breast: evidence of a basal-like subset? Hum Pathol 39: 331-336, 2008.

4. Lee HJ, Seo AN, Kim EJ, Jang MH, Kim YJ, Kim JH, Kim SW, Ryu HS, Park IA, Im SA, et al: Prognostic and predictive values of EGFR overexpression and EGFR copy number alteration in HER2-positive breast cancer. Br J Cancer 112: 103-111, 2015.

5. Park HS, Jang MH, Kim EJ, Kim HJ, Lee HJ, Kim YJ, Kim JH, Kang E, Kim SW, Kim IA and Park SY: High EGFR gene copy number predicts poor outcome in triple-negative breast cancer. Mod Pathol 27: 1212-1222, 2014.

6. Rakha EA, El-Sayed ME, Green AR, Lee AH, Robertson JF and Ellis IO: Prognostic markers in triple-negative breast cancer. Cancer 109: 25-32, 2007.

7. Sood N and Nigam JS: Correlation of CK5 and EGFR with clinicopathological profile of triple-negative breast cancer. Patholog Res Int 2014: 141864, 2014.

8. Niemeier LA, Dabbs DJ, Beriwal S, Striebel JM and Bhargava R: Androgen receptor in breast cancer: expression in estrogen receptor-positive tumors and in estrogen receptor-negative tumors with apocrine differentiation. Mod Pathol 23: 205-212, 2010.

9. Prat A, Parker JS, Karginova O, Fan C, Livasy C, Herschkowitz JI, He X and Perou CM: Phenotypic and molecular characterization of the claudin-low intrinsic subtype of breast cancer. Breast Cancer Res 12: R68, 2010.

10. Lehmann BD, Bauer JA, Chen X, Sanders ME, Chakravarthy AB, Shyr Y and Pietenpol JA: Identification of human triple-negative breast cancer subtypes and preclinical models for selection of targeted therapies. J Clin Invest 121: 2750-2767, 2011.

11. Turner NC and Reis-Filho JS: Tackling the diversity of triple-negative breast cancer. Clin Cancer Res 19: 6380-6388, 2013.

12. Lehmann BD and Pietenpol JA: Identification and use of biomarkers in treatment strategies for triple-negative breast cancer subtypes. J Pathol 232: 142-150, 2014.

13. Prat A, Adamo B, Cheang MC, Anders CK, Carey LA and Perou CM: Molecular characterization of basal-like and non-basal-like triple-negative breast cancer. Oncologist 18: 123-133, 2013.

14. Abramson VG, Lehmann BD, Ballinger TJ and Pietenpol JA: Subtyping of triple-negative breast cancer: implications for therapy. Cancer 121: 8-16, 2015. 
15. Schmadeka R, Harmon BE and Singh M: Triple-negative breast carcinoma: current and emerging concepts. Am J Clin Pathol 141: 462-477, 2014

16. Choo JR and Nielsen TO: Biomarkers for basal-like breast cancer. Cancers (Basel) 2: 1040-1065, 2010.

17. Ricardo S, Vieira AF, Gerhard R, Leitão D, Pinto R, CameselleTeijeiro JF, Milanezi F, Schmitt F, Paredes J. Breast cancer stem cell markers CD44, CD24 and ALDH1: expression distribution within intrinsic molecular subtype. J Clin Pathol 64: 937-946, 2011.

18. Mylona E, Giannopoulou I, Fasomytakis E, Nomikos A, Magkou C, Bakarakos P, Nakopoulou L. The clinicopathologic and prognostic significance of $\mathrm{CD} 44^{+} / \mathrm{CD} 24^{\text {(-llow) }}$ and CD $44^{-} / \mathrm{CD} 24^{+}$tumor cells in invasive breast carcinomas. Hum Pathol 39:1096-1102, 2008

19. Mayer IA, Abramson VG, Lehmann BD and Pietenpol JA: New strategies for triple-negative breast cancer - deciphering the heterogeneity. Clin Cancer Res 20: 782-790, 2014.

20. Neve RM, Chin K, Fridlyand J, Yeh J, Baehner FL, Fevr T, Clark L, Bayani N, Coppe JP, Tong F, et al: A collection of breast cancer cell lines for the study of functionally distinct cancer subtypes. Cancer Cell 10: 515-527, 2006

21. Kao J, Salari K, Bocanegra M, Choi YL, Girard L, Gandhi J, Kwei KA, Hernandez-Boussard T, Wang P, Gazdar AF, et al: Molecular profiling of breast cancer cell lines defines relevant tumor models and provides a resource for cancer gene discovery. PLoS One 4: e6146, 2009.

22. Liu T, Zhang X, Shang M, Zhang Y, Xia B, Niu M, Liu Y and Pang D: Dysregulated expression of Slug, vimentin and E-cadherin correlates with poor clinical outcome in patients with basal-like breast cancer. J Surg Oncol 107: 188-194, 2013

23. Lee J, Hahm ER, Marcus AI and Singh SV: Withaferin A inhibits experimental epithelial-mesenchymal transition in MCF-10A cells and suppresses vimentin protein level in vivo in breast tumors. Mo Carcinog 54: 417-429, 2015.

24. Rito M, Schmitt F, Pinto AE and André S: Fibromatosis-like metaplastic carcinoma of the breast has a claudin-low immunohistochemical phenotype. Virchows Arch 465: 185-191, 2014.

25. Zhang Y, Toy KA and Kleer CG: Metaplastic breast carcinomas are enriched in markers of tumor-initiating cells and epithelial to mesenchymal transition. Mod Pathol 25: 178-184, 2012.

26. Giatromanolaki A, Sivridis E, Fiska A and Koukourakis MI: The CD44+/CD24- phenotype relates to 'triple-negative' state and unfavorable prognosis in breast cancer patients. Med Oncol 28 745-752, 2011.

27. Honeth G, Bendahl PO, Ringner M, Ringnér M, Saal LH, Gruvberger-Saal SK, Lövgren K, Grabau D, Fernö M, Borg A and Hegardt C: The CD44+/CD24-phenotype is enriched in basal-like breast tumors. Breast Cancer Res 10: R53, 2008

28. Hammond ME, Hayes DF, Wolff AC, Mangu PB and Temin S: American Society of Clinical Oncology/College of American Pathologists guideline recommendations for immunohistochemical testing of estrogen and progesterone receptors in breast cancer. J Oncol Pract 6: 195-197, 2010.

29. Barry WT, Kernagis DN, Dressman HK, Griffis RJ, Hunter JD, Olson JA, Marks JR, Ginsburg GS, Marcom PK, Nevins JR, et al: Intratumor heterogeneity and precision of microarray-based predictors of breast cancer biology and clinical outcome. J Clin Oncol 28: 2198-2206, 2010.

30. Prat A, Parker JS, Fan C and Perou CM: PAM50 assay and the three-gene model for identifying the major and clinically relevant molecular subtypes of breast cancer. Breast Cancer Res Treat 135 301-306, 2012

31. Nielsen TO, Hsu FD, Jensen K, Cheang M, Karaca G, Hu Z, Hernandez-Boussard T, Livasy C, Cowan D, Dressler L, et al: Immunohistochemical and clinical characterization of the basal-like subtype of invasive breast carcinoma. Clin Cancer Res 10: 5367-5374, 2004.

32. Badve S, Dabbs DJ, Schnitt SJ, Baehner FL, Decker T, Eusebi V, Fox SB, Ichihara S, Jacquemier J, Lakhani SR, et al: Basal-like and triple-negative breast cancers: a critical review with an emphasis on the implications for pathologists and oncologists. Mod Pathol 24: 157-167, 2011.

33. Choi YL, Oh E, Park S, Kim Y, Park YH, Song K, Cho EY, Hong YC, Choi JS, Lee JE, et al: Triple-negative, basal-like and quintuple-negative breast cancers: better prediction model for survival. BMC Cancer 10: 507,2010.

34. Won JR, Gao D, Chow C, Cheng J, Lau SY, Ellis MJ, Perou CM, Bernard PS and Nielsen TO: A survey of immunohistochemical biomarkers for basal-like breast cancer against a gene expression profile gold standard. Mod Pathol 26: 1438-1450, 2013.
35. Safarpour D, Pakneshan S and Tavassoli FA: Androgen receptor (AR) expression in 400 breast carcinomas: is routine $\mathrm{AR}$ assessment justified? Am J Cancer Res 4: 353-368, 2014.

36. McNamara KM, Yoda T, Miki Y, Chanplakorn N, Wongwaisayawan S, Incharoen P, Kongdan Y, Wang L, Takagi K, Mayu T, et al: Androgenic pathway in triple negative invasive ductal tumors: its correlation with tumor cell proliferation. Cancer Sci 104: 639-646, 2013.

37. Tsutsumi Y: Apocrine carcinoma as triple-negative breast cancer: novel definition of apocrine-type carcinoma as estrogen/progesterone receptor-negative and androgen receptor-positive invasive ductal carcinoma. Jpn J Clin Oncol 42: 375-386, 2012.

38. Thike AA, Yong-Zheng Chong L, Cheok PY, Li HH, Wai-Cheong Yip G, Huat Bay B, Tse GM, Iqbal J and Tan PH: Loss of androgen receptor expression predicts early recurrence in triple-negative and basal-like breast cancer. Mod Pathol 27: 352-360, 2014.

39. Tsang JY, Ni YB, Chan SK, Shao MM, Law BK, Tan PH and Tse GM: Androgen receptor expression shows distinctive significance in ER positive and negative breast cancers. Ann Surg Oncol 21: 2218-2228, 2014.

40. Pistelli M, Caramanti M, Biscotti T, Santinelli A, Pagliacci A, De Lisa M, Ballatore Z, Ridolfi F, Maccaroni E, Bracci R, et al: Androgen receptor expression in early triple-negative breast cancer: clinical significance and prognostic associations. Cancers (Basel) 6: 1351-1362, 2014.

41. McNamara KM, Yoda T, Takagi K, Miki Y, Suzuki T and Sasano H: Androgen receptor in triple negative breast cancer. J Steroid Biochem Mol Biol 133: 66-76, 2013.

42. Gasparini P, Fassan M, Cascione L, Guler G, Balci S, Irkkan C, Paisie C, Lovat F, Morrison C, Zhang J, et al: Androgen receptor status is a prognostic marker in non-basal triple negative breast cancers and determines novel therapeutic options. PLoS One 9: e88525, 2014

43. Loibl S, Müller BM, von Minckwitz G, Schwabe M, Roller M, Darb-Esfahani S, Ataseven B, du Bois A, Fissler-Eckhoff A, Gerber B, et al: Androgen receptor expression in primary breast cancer and its predictive and prognostic value in patients treated with neoadjuvant chemotherapy. Breast Cancer Res Treat 130: 477-487, 2011.

44. Micello D, Marando A, Sahnane N, Riva C, Capella C and Sessa F: Androgen receptor is frequently expressed in HER2-positive, ER/PR-negative breast cancers. Virchows Arch 457: 467-476, 2010.

45. Ogawa Y, Hai E, Matsumoto K, Ikeda K, Tokunaga S, Nagahara H, Sakurai K, Inoue T and Nishiguchi Y: Androgen receptor expression in breast cancer: relationship with clinicopathological factors and biomarkers. Int J Clin Oncol 13: 431-435, 2008.

46. Witzel I, Graeser M, Karn T, Schmidt M, Wirtz R, Schütze D, Rausch A, Jänicke F, Milde-Langosch K and Müller V: Androgen receptor expression is a predictive marker in chemotherapy-treated patients with endocrine receptor-positive primary breast cancers. J Cancer Res Clin Oncol 139: 809-816, 2013.

47. Tang $\mathrm{D}, \mathrm{Xu} \mathrm{S}$, Zhang Q and Zhao W: The expression and clinical significance of the androgen receptor and E-cadherin in triple-negative breast cancer. Med Oncol 29: 526-533, 2012.

48. Hu R, Dawood S, Holmes MD, Collins LC, Schnitt SJ, Cole K, Marotti JD, Hankinson SE, Colditz GA and Tamimi RM: Androgen receptor expression and breast cancer survival in postmenopausal women. Clin Cancer Res 17: 1867-1874, 2011.

49. Lu S, Singh K, Mangray S, Tavares R, Noble L, Resnick MB and Yakirevich E: Claudin expression in high-grade invasive ductal carcinoma of the breast: correlation with the molecular subtype. Mod Pathol 26: 485-495, 2013.

50. Gerhard R, Ricardo S, Albergaria A, Gomes M, Silva AR, Logullo ÂF, Cameselle-Teijeiro JF, Paredes J and Schmitt F: Immunohistochemical features of claudin-low intrinsic subtype in metaplastic breast carcinomas. Breast 21: 354-360, 2012 .

51. Sabatier R, Guille A, Adelaide J, Chaffanet M, Viens P, Birnbaum D, Bertucci F and Finetti P: Claudin-low breast cancers: clinical, pathological, molecular and prognostic characterization. Mol Cancer 13: 228, 2014

52. MasudaH,Baggerly KA,Wang Y,Zhang Y,Gonzalez-Angulo AM, Meric-Bernstam F, Valero V, Lehmann BD, Pietenpol JA, Hortobagyi GN, et al: Differential response to neoadjuvant chemotherapy among 7 triple-negative breast cancer molecular subtypes. Clin Cancer Res 19: 5533-5540, 2013. 